\title{
Cazadores-recolectores y pastores en los Andes (San Juan, Argentina): cambios en la organización tecnológica durante el Holoceno
}

( Silvina C. Castro*
Recibido: 21 de febrero de 2017

Aceptado:

5 de julio de 2017

\section{Resumen}

El alero ARQ-18, emplazado en la cordillera (noroeste de San Juan), posee una secuencia ocupacional amplia (ca. 8000 años). Un hiato de 1600 años durante el Holoceno medio separa ocupaciones de cazadores-recolectores con alta movilidad residencial y ocupaciones de pastores trashumantes. Se evalúan cambios en la organización tecnológica vinculados a transformaciones en la subsistencia y la movilidad. Se analiza procedencia de recursos, densidad de piezas, secuencias reductivas, variabilidad artefactual y clases técnicas. Los resultados indican que el paso hacia una economía diversificada resultó en estadías más largas, diversificación de tareas, desarrollo de estrategias fundamentalmente expeditivas y oportunísticas, estrategias conservadas vinculadas a la caza y una disminución en la inversión de trabajo para la manufactura de instrumentos.

\section{Hunter-gatherers and herders in the Andes (San Juan, Argentina): changes in technological organization during the Holocene}

\begin{abstract}
The ARQ-18 rock shelter, located in the northwestern cordillera of the San Juan Province of Argentina, has a long occupational sequence (ca. 8,000 years BP). A middle Holocene hiatus of 1,600 years separates high residential mobility hunter-gatherer occupation from transhumant herder occupation. This article evaluates changes in the organization of lithic technology linked to transformations in subsistence and mobility. Our analysis addresses the origin of resources, artifact density, reduction sequences, artifact variability, and technical classes. The data demonstrates that the transition to a diversified economy resulted in longer stays, a greater diversity of tasks, the use of mostly expedient and opportunistic strategies, and a decrease in time invested in the making of lithic implements. Curation strategies are linked to a continuity of hunting as an economic activity.
\end{abstract}

\footnotetext{
* Laboratorio de Paleoecología Humana, Facultad de Ciencias Exactas y Naturales, Universidad Nacional de Cuyo (UNCu) - CONICET. Padre Jorge Contreras 1300, Parque General San Martín (CP M5502JMA) Mendoza, Argentina. E-mail: silvinacastro2015@gmail.com
}

\section{Palabras clave}

Organización tecnológica Cazadores-recolectores

Pastores

Ambiente de altura

Keywords

Technological organization Hunter-gatherers

Herders

High altitude environment 


\section{Introducción}

Se estudia la organización tecnológica de sociedades con diferentes estrategias de subsistencia que ocuparon estacionalmente la cuenca alta del río de las Taguas (Noroeste de San Juan) a lo largo de casi todo el Holoceno. Los datos proceden del registro lítico del sitio ARQ-18 (3.761 m s.n.m.), alero acondicionado con una secuencia ocupacional amplia entre ca. 8900 y 790 años AP (Castro, 2015).

Características cronológicas y estratigráficas del sitio permitieron definir cinco componentes de ocupación, C-V a C-I (Cortegoso, 2014). Una disrupción cronológica de casi 1600 años (ca. 6700-5100 años AP), vinculada a la hiperaridez del Holoceno medio y a la consecuente reconfiguración de los circuitos de movilidad de los grupos, separa componentes con características estratigráficas y contextuales diferentes y que han sido vinculados a grupos con estrategias económicas también diferentes. Previo al hiato, C-V (8900-8000 años AP) y C-IV (7300-6700 años AP) están conformados por capas estratigráficas naturales donde predomina el material lítico mientras que los registros botánico y óseo son muy escasos y poco diversos. Estas ocupaciones corresponden a sociedades con economías extractivas y altamente móviles (Castro, Gasco, Lucero y Cortegoso, 2013; Cortegoso, 2014; Cortegoso et al., 2012a; Gasco, 2014; Llano y Fernández, 2014). Estos componentes están separados de los estratigráficamente superiores por dos extracciones de $5 \mathrm{~cm}$ cada una que corresponden a un hiato ocupacional (Cortegoso, 2014). En estas extracciones no se registró material orgánico, sólo se recuperó un exiguo registro lítico resultado de un proceso tafonómico de migración de materiales procedentes de capas superiores (Castro, 2015). Este material integra un conjunto denominado Z (CJ-Z), herramienta analítica que permitió evaluar el registro aisladamente de los componentes crono-estratigráficos. Posterior al hiato, C-III (5100-4300 años AP), C-II (3700 años AP) y C-I (3000-1500 años AP) están conformados por capas antrópicas generadas por espacios internos delimitados mediante grandes rocas y acondicionados con camadas de gramíneas (Cortegoso, 2014). En el interior de estos espacios se registraron fogones con restos de excretas animales y diversos materiales asociados (lítico, huesos, semillas), equipamiento de sitio, instrumental posiblemente vinculado a tareas textiles, mayor cantidad y diversidad de macrorrestos botánicos y de camélidos (Castro et al., 2013; Durán y Cortegoso, 2008; Gasco, 2014; Llano y Fernández, 2014). Análisis osteométricos registraron el morfotipo Lama glama desde el C-III (Gasco, 2014). En función a dichas características contextuales y del registro arqueológico se propuso que estas ocupaciones podrían corresponder a grupos de pastores con sistemas de movilidad trashumante (Castro et al., 2013; Gasco, 2014).

Así, ARQ-18 registraría una de las evidencias más tempranas en el país para animales domésticos (ca. 5100-4500 años AP). Esta propuesta de domesticación temprana puede entenderse como parte de un proceso de transición hacia la domesticación de camélidos cuyo inicio ha sido registrado en Antofagasta de la Sierra, área relativamente próxima, entre ca. 5500 y 5000 años AP (Aschero y Hocsman, 2011; Escola, 1996; Yacobaccio, 2006). Este proceso tiene su correlato en la tecnología lítica, la cual se caracteriza por una disminución en la inversión de trabajo para la manufactura de herramientas, excepto la tecnología de caza que continúa vinculada a técnicas de talla que requieren mayor esfuerzo en la manufactura (Escola, 2000; Hocsman, 2014).

El objetivo del presente trabajo es evaluar si el registro lítico de ARQ-18 $(\mathrm{n}=16224)$ evidencia cambios en la organización tecnológica (sensu Nelson, 1991) que acompañen el posible proceso que llevó de un modo de vida cazador-recolector a otro que incluyó la domesticación de camélidos. Mediante el análisis de diversas variables del registro se indagará sobre las estrategias que permitieron a los grupos enfrentar el riesgo vinculado a los diferentes tipos de subsistencia (sensu Torrence, 1989). 
La estructura del trabajo incluye: caracterización general del área de estudio, síntesis sobre la disponibilidad de recursos líticos, análisis del registro, discusión y conclusiones.

\section{Área de estudio: características ambientales y articulación con la vertiente occidental de los Andes}

La cuenca alta del río de Las Taguas se encuentra en un ambiente andino flanqueado por cordones montañosos que superan los $5.500 \mathrm{~m}$ s.n.m. al Oeste y los $5.000 \mathrm{~m}$ s.n.m. al Este (Figura 1). Las cotas más bajas corresponden al valle del río de Las Taguas a 3.700 m s.n.m., ubicado en el centro del área de estudio. Las fuertes precipitaciones níveas y las bajas temperaturas disminuyen las posibilidades de uso durante el invierno, por tanto su explotación debió ocurrir mayoritariamente durante los meses de verano. Este ambiente cuenta con abundantes recursos imprescindibles para la subsistencia, como agua, animales y forraje. Los recursos bióticos tienen una distribución heterogénea, estando disponibles durante la estación primavera-verano, concentrados en las zonas de valle y casi ausentes en los sectores de mayor altitud. La principal fauna silvestre del área son los camélidos (Lama guanicoe).

Debido a su ubicación geográfica este sector cordillerano es un enclave entre importantes regiones arqueológicas de Argentina y Chile. Esto ha orientado interrogantes vinculados con la procedencia de los grupos que lo explotaban y los ambientes en los que completaban los circuitos anuales de movilidad. Los estudios iniciados exploran fundamentalmente la articulación de este espacio con la vertiente occidental de la cordillera. Se trata de ambientes complementarios, ya que las regiones del Norte Semiárido Chileno sufren la estación seca durante el verano cuando en el área de estudio se da la estación húmeda. En función de la correlación de las ocupaciones de ARQ-18 con fases climáticas del Norte Semiárido Chileno caracterizadas por la sincronía de condiciones húmedas y frías en sectores cordilleranos y áridas en sectores bajos (Figura 2), se propuso que la explotación del valle del Taguas pudo funcionar como una estrategia para enfrentar el estrés hídrico en las zonas bajas de Chile (Cortegoso, Durán, Castro y Winocur, 2012b; Marsh, Cortegoso y Castro, 2016). A su vez, estudios predictivos realizados con Sistemas de Información Geográfica indican que las rutas de menor costo hacia el valle del Taguas proceden de los valles del Huasco y Elqui en el Norte Semiárido Chileno (Lucero, Marsh y Castro, 2014). Además, análisis macrobotánicos indican que plantas alóctonas registradas en ARQ-18 procederían de la vertiente cordillerana occidental (Llano y Fernández, 2014).

\section{Disponibilidad de recursos líticos}

La base regional de recursos líticos fue reconstruida por medio de trabajos multidisciplinarios arqueológicos, geológicos y de Sistemas de Información Geográfica (Castro, Lucero, Cortegoso y Winocur, 2014; Cortegoso et al., 2012b; Lucero, Castro, Marsh y Cortegoso, 2016). Se detectaron siete fuentes de materia prima, fundamentalmente de rocas silíceas criptocristalinas, en tres sectores altitudinales. En la franja de mayor altitud ( $\geq 4.000 \mathrm{~m}$ s.n.m.) las fuentes ARQ-C15 y ARQ-C14 poseen rocas de calidad regular para la talla ${ }^{1}$. En la franja intermedia (4.000-3.800 m s.n.m.) las fuentes Potrerillos A, Potrerillos B, Guanaco Zonzo y Amarillos presentan rocas de muy buena calidad. En la franja de menor altitud (< $3.800 \mathrm{~m}$ s.n.m.) la fuente Taguas cuenta con rocas de buena calidad. Además, se registran silíceas criptocristalinas de excelente calidad para la talla de procedencia indeterminada, cuyas fuentes potenciales podrían encontrarse en Combarbalá (Norte Semiárido Chileno) donde se han registrado rocas con características litológicas similares (Solar, Méndez, Jackson y López, 2010).
1. Se entiende que los mejores recursos para la talla son aquellos que poseen fractura concoidal (Andrefsky, 1998; Dibble, 1992) y se consideran procesos mecánicos y térmicos que afectan la calidad de la roca, debido al ambiente periglaciar. Se emplean tres categorías de calidad: 1- Muy Buena, 2- Buena y 3- Regular (Castro et al., 2014).

2. Las fuentes Guanaco Zonzo y Potrerillos B son presentadas conjuntamente (G.Z/P.B) ya que presentan rocas silíceas con características macroscópicas semejantes (Castro et al., 2014). 


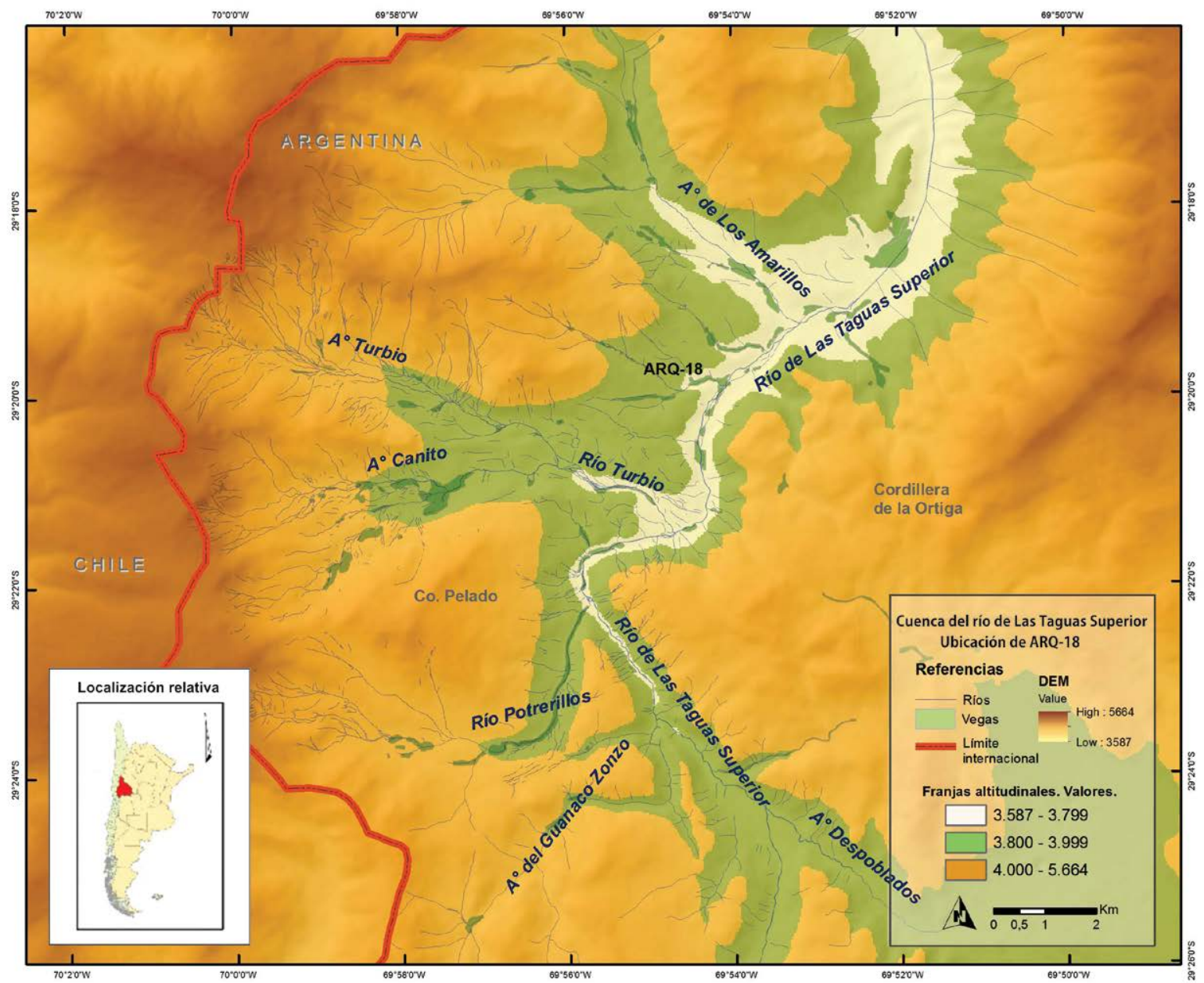

Figura 1. Cuenca Superior del río de Las Taguas.

3. La pendiente se modeló mediante un mosaico georreferenciado de 34 escenas digitales de elevación obtenido de la fuente ASTER GDEM v2, con una resolución de 1 arco segundo y una proyección plana UTM, las celdas son $\sim 30 \mathrm{x}$ 30 m cada una (Tachikawa, Hato, Kaku y lwasaki, 2011). Usando el programa ArcGIS 10.1 se utilizó la herramienta Path Distance para generar una superficie de fricción que representa variaciones en la distancia debido a la pendiente. Se aplicó al modelo anisotrópico la función Hiking de Tobler (1993) y se obtuvo un gráfico del tiempo de traslado desde un punto central hacia puntos periféricos por medio

de líneas isócronas de 2 horas

cada una.

4. Entre los recursos locales se incluye una subcategoría denominada fuentes no posicionadas (Locales NP), es decir rocas cuya ubicación específica dentro del área es desconocida.
La discriminación entre procedencia local y no local se efectuó mediante un análisis de Sistemas de Información Geográfica ${ }^{3}$ que considera los altos costos de movilidad que imponen las topografías abruptas (Lucero et al., 2016). La distancia recorrida en una cantidad de tiempo determinado varía según la pendiente y el uso de vías de circulación naturales. Por lo tanto el costo de accesibilidad a los recursos se midió en tiempo de traslado y se consideró apropiado clasificar como local el espacio al que puede accederse en una jornada de 8 horas. Este análisis indico que en el valle del Taguas todas las fuentes registradas serían de procedencia local.

El análisis espacial también se aplicó para calcular los costos de accesibilidad desde ARQ18 a cada una de las fuentes locales y se estableció un ranking donde los valores más bajos indican costos menores (Tabla 1). Luego se calculó la relación (R) entre costo de accesibilidad (A) y calidad (C) de los recursos mediante el producto de ambos factores $\left(R=A^{*} C\right)$. En esta relación los valores más bajos indican fuentes más atractivas para su explotación, es decir más accesibles y con recursos de mejor calidad (Tabla 1). Esto permitirá evaluar la vinculación entre la explotación diferencial de las fuentes locales de materias primas con el costo de accesibilidad y la calidad para la talla que presentan los recursos.

\section{Análisis lítico}

Para el análisis lítico se seleccionaron variables que se consideran sensibles a cambios en la intensidad de ocupación del sitio, los patrones de movilidad y el riesgo vinculado a la 


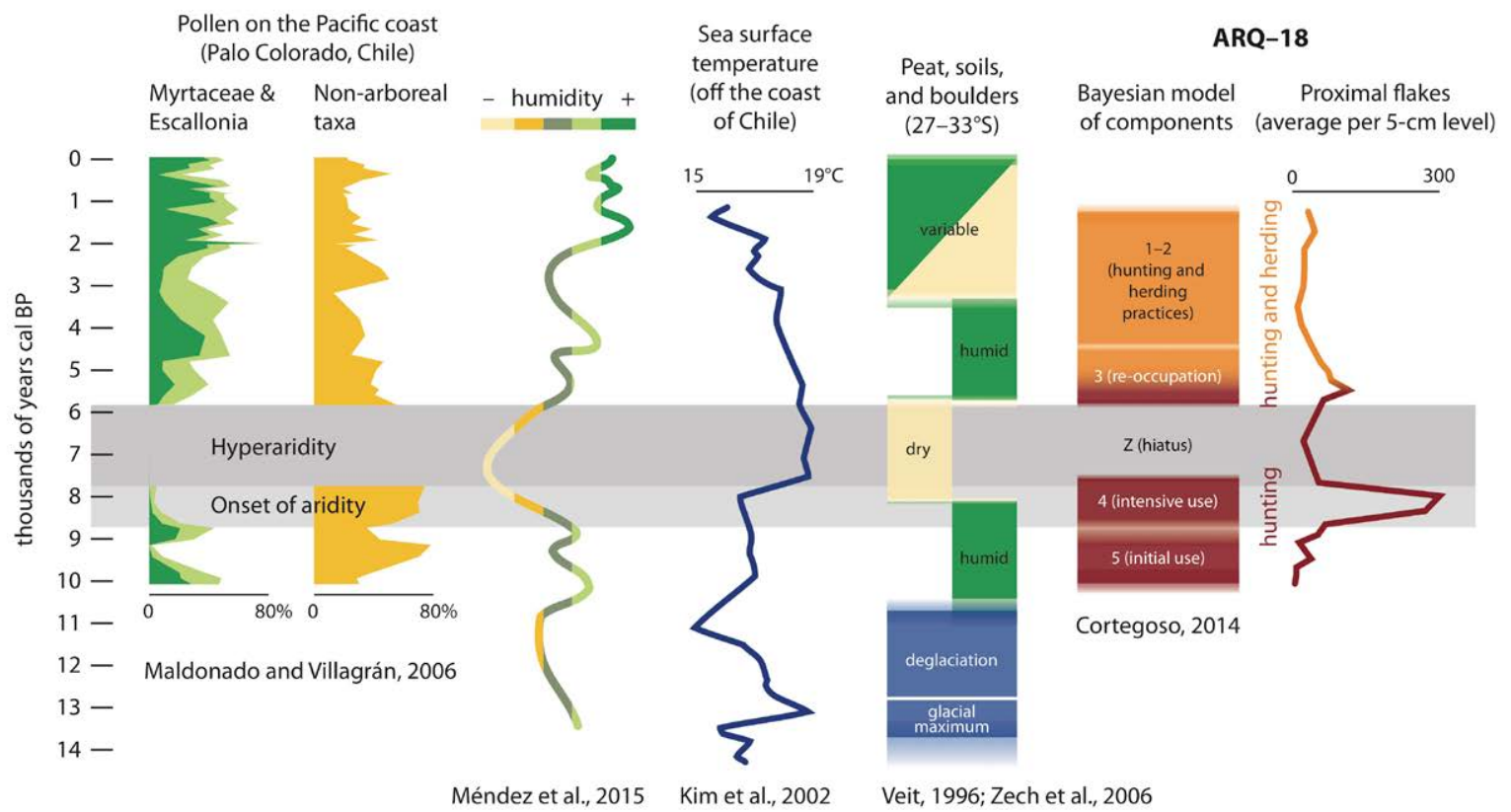

Figura 2. Correlación de condiciones paleoambientales y cronología de ARQ-18 (tomado de Marsh et al., 2016).

\begin{tabular}{|l|c|c|c|c|c|c|}
\hline Fuente & $\begin{array}{c}\text { Altitud } \\
(\mathrm{msnm})\end{array}$ & $\begin{array}{c}\text { Distancia } \\
(\mathbf{k m})\end{array}$ & $\begin{array}{c}\text { Costo de } \\
\text { Accesibilidad } \\
(\mathbf{h s})\end{array}$ & $\begin{array}{c}\text { Ranking } \\
\text { Costo }(\mathbf{A})\end{array}$ & $\begin{array}{c}\text { Calidad } \\
\text { MP (C) }\end{array}$ & R=A*C \\
\hline Taguas & 3.700 & 1.5 & 0,38 & 1 & 2 & 2 \\
Amarillos & 3.900 & 4.7 & 1,18 & 2 & 1 & 2 \\
Potrerillos A & 3.900 & 6.1 & 1,53 & 3 & 1 & 3 \\
Potrerillos B & 3.920 & 6.4 & 1,60 & 4 & 2 & 8 \\
Guanaco Zonzo & 3.800 & 9.6 & 2,40 & 5 & 2 & 10 \\
ARQ-C14 & 4.300 & 11.2 & 2,80 & 6 & 2 & 12 \\
ARQ-C15 & 4.500 & 12.7 & 3,18 & 7 & 3 & 21 \\
\hline
\end{tabular}

Tabla 1. Ranking de fuentes líticas desde el sitio $A R Q-18$.

adquisición de alimentos (Binford, 1979; Bleed, 1986; Clarkson, 2008; Gould y Saggers, 1985; Kuhn, 2004; Shott, 1986; Torrence, 1986; entre otros). El análisis es macroscópico y morfológico-descriptivo (Aschero, 1975; Aschero y Hocsman, 2004). Se calcula la densidad de elementos $(d)$ considerando la totalidad del registro de cada conjunto. El número mínimo de golpes efectuados (NMGE) se infiere del número de lascas proximales (Andrefsky, 1998, p. 89). Para el análisis de explotación de materias primas se consideran los estudios sobre disponibilidad de recursos líticos explicitados en el apartado anterior. La reconstrucción de secuencias reductivas considera siete etapas desde la obtención de recursos hasta las actividades de mantenimiento ${ }^{5}$ (Cortegoso, 2004). Para evaluar la diversidad artefactual se calcula la media de subgrupos tipológicos: cociente entre el total de subtipos y el total de tipos morfológicos de instrumentos (sensu Hocsman, 2014). Las clases técnicas, en orden creciente de inversión de trabajo, son: 1-trabajo bipolar, 2-trabajo no invasivo alternante, 3-trabajo no invasivo unifacial, 4-trabajo no invasivo bifacial, 5-reducción unifacial, 6-adelgazamiento unifacial, 7-reducción bifacial y 8-adelgazamiento bifacial (Aschero y Hocsman, 2004; Hocsman

5. Adquisición (formas naturales), Preparación (núcleos e indiferenciados), Talla Primaria (lascas externas), Talla Secundaria (lascas internas), Formatización (micro y ultramicrolascas), Instrumentos (artefactos formatizados y litos modificados por uso) y Mantenimiento (lascas de reactivación de filo). 
el valor 0 para aquellos artefactos sin formatización. El incremento en el valor refleja mayor inversión de trabajo y se discrimina entre valores nulo (0), muy bajo (1), bajos $(2,3,4)$, medios $(5,6)$ y altos $(7,8)$.

\section{Composición general de las muestras y explotación de recursos líticos}

El registro lítico de $\mathrm{C}-\mathrm{V}$ es uno de los menos abundantes del sitio y la $d$ de piezas y el NMGE c/100 años son bajos en comparación con el resto de los conjuntos (Tabla 2). El conjunto de C-IV es el más abundante del sitio y posee la mayor $d$ de piezas y NMGE c/100 años. El CJ-Z presenta la muestra lítica más pequeña de todo el sitio, registra una caída abrupta de la $d$ de piezas y el NMGE c/100 años. El registro lítico de C-III es el segundo más abundante del sitio. La $d$ de piezas y el NMGE c/100 años son muy superiores a los de C-V e inferiores a los de C-IV. El registro del C-II es el menos abundante de los componentes. No se calcula $d$ ni NMGE c/100 años ya que no es posible estimar un rango temporal para este componente para el cual se cuenta con único fechado. La muestra lítica de C-I es la segunda menos abundante. La $d$ de piezas y el NMGE c/100 años son los más bajos entre los componentes del sitio.

En todos los componentes las rocas más representadas son silíceas criptocristalinas (entre $80 \%$ y $94 \%$ ), vinculado a su mejor calidad para la talla y a la alta disponibilidad en fuentes locales. El resto de los tipos están escasamente representados (tobas, tufitas, riolitas, andesitas, cuarzos y granito). Predominan rocas de procedencia local (Tabla 3), con porcentajes mayores en C-V (96\%) y C-IV (95\%) y un descenso a partir del CJ-Z (91\%) y los componentes posteriores C-III (81,5\%), C-II (89\%) y C-I (66\%). Las rocas de procedencia indeterminada, posiblemente foráneas, tienen los porcentajes más bajos en C-V (4\%) y C-IV (5\%) y se incrementan a partir de CJ-Z (9\%) y los componentes C-III (18,5\%), C-II (11\%) y C-I (34\%).

En cuanto a fuentes locales, Potrerillos A es la más representada (Tabla 3). Esto puede deberse a que es la tercer fuente más atractiva por su relación costo-calidad (Tabla 1) y a que ofrece nódulos con escasa corteza, de gran tamaño $(>20 \mathrm{~cm})$ y de fácil extracción (Castro et al., 2014). Además se ubica en una de las rutas de menor costo que conecta el área de estudio con el valle del Elqui al oeste de la cordillera (Lucero et al., 2014). A partir de C-III disminuye la representación de Potrerillos A, se incrementa la de Amarillos y, en menor medida, la del resto de las fuentes locales (Tabla 3). Amarillos fue rankeada como una de las dos fuentes más atractivas para la explotación (Tabla 1) y se encuentra en otra ruta de menor costo que conecta el área con el valle del Huasco en Chile (Lucero et al., 2014).

Las fuentes menos representadas en todos los conjuntos son Taguas, ARQ-C15, ARQC14 y G.Z/P.B. La fuente Taguas presenta una relación costo-calidad muy buena (Tabla 1), sin embargo los costos de extracción pudieron ser altos ya que la roca aparece en forma de vetas. Además, se ubica en el límite este del área de estudio, fuera de las rutas de acceso al valle desde la vertiente occidental andina. ARQ-C15 y ARQ-C14 presentan recursos de calidad regular y altos costos de accesibilidad (Tabla 1), sin embargo estos recursos se registran en todos los componentes. Las fuentes se emplazan en la ruta de conexión con el valle del Elqui y la adquisición de estos materiales pudo realizarse durante el ingreso al área a través de una estrategia de tipo embedded (Binford, 1979).

Las rocas locales NP se encuentran en todos los registros con porcentajes altos (Tabla 3), lo que puede evidenciar la existencia de rangos de adquisición que involucraron un área más amplia que la sistemáticamente relevada en los trabajos de campo (Gould y Saggers, 1985). 


\begin{tabular}{|l|c|c|c|c|}
\hline & Cantidad & Representación & d c/100 años & NMGE c/100 años \\
\hline C-V & 1.881 & $12 \%$ & 213,75 & 27 \\
C-IV & 7.037 & $43 \%$ & 1153 & 219 \\
CJ-Z & 219 & $1 \%$ & 13,68 & 1,8 \\
C-III & 4.675 & $29 \%$ & 577,16 & 89 \\
C-II & 680 & $4 \%$ & - & - \\
C-I & 1.732 & $11 \%$ & 120,27 & 19 \\
Total & 16.224 & $100 \%$ & - & - \\
\hline
\end{tabular}

Tabla 2. Composición general de la muestra lítica de cada componente. Referencias: d: densidad de elementos; NMGE: número mínimo de golpes efectuados.

\section{Secuencias de reducción lítica}

En todos los componentes la actividad de talla se concentró en la elaboración de instrumentos (entre $60 \%$ y $80 \%$ ) mientras que la adquisición de materia prima, la preparación de núcleos y el descarte y mantenimiento de instrumentos son las tareas menos representadas. A pesar de esta caracterización general, se observan algunas diferencias entre componentes.

En C-V la secuencia reductiva se concentra en las categorías de Preparación (10,3\%), Talla Secundaria (14,35\%) y Formatización (74\%). En C-IV continúan predominando las categorías Preparación (9\%), Talla Secundaria (20\%) y Formatización (68\%), aunque se observa una disminución de ésta última y un incremento de la Talla Secundaria y Talla Primaria (2,6\%) relacionadas con la obtención de soportes. En la Talla Secundaria se registran lascas de adelgazamiento bifacial, estas piezas representan, en $\mathrm{C}-\mathrm{V}$ y C-IV, el $15 \%$ y $13 \%$ de dicha etapa reductiva. En ambos componentes la categoría Instrumentos tiene baja representación $(0,6 \%$ y $0,4 \%)$.

En el CJ-Z la secuencia de reducción se limita prácticamente a la Formatización $(83,5 \%)$, categoría que registra el mayor porcentaje de todo el sitio. El resto de las piezas conforma, las categorías Talla Secundaria (16\%) e Instrumentos (0,5\%). Las lascas de adelgazamiento bifacial representan el $14 \%$ de la Talla Secundaria.

En las secuencias de C-III y C-II comienzan a disminuir las categorías Preparación (4\% y $5 \%$ ) y Talla Secundaria (16\% y $14 \%$ ) y se incrementan la Formatización (77\% y $78 \%$ ) y los Instrumentos (1\% en ambos casos). En C-III, las lascas de adelgazamiento bifacial representan el $12 \%$ de la Talla Secundaria. En C-II no se registran lascas de adelgazamiento bifacial. En los dos componentes la Talla Primaria mantiene porcentajes bajos (2\% en ambos casos).

Finalmente el C-I registra la única secuencia completa del sitio y una diversificación de las categorías representadas. La categoría de Formatización continúa siendo la de mayor representación pero con el porcentaje más bajo de toda la secuencia $(62,4 \%)$. Por el contrario se incrementa el porcentaje de las etapas iniciales y finales, como Adquisición (2\%), Preparación (11,3\%), Instrumentos (3\%), Mantenimiento (0,3\%). Se registran por primera vez fragmentos naturales y lascas de reactivación de filos, que conforman las categorías Adquisición y Mantenimiento. Las Talla Primaria (2\%) y Talla Secundaria (19\%) mantienen porcentajes semejantes a los conjuntos anteriores. Las lascas de adelgazamiento bifacial representan el 1,5\% de la Talla Secundaria.

En todos los conjuntos se registran entre las micro y ultramicrolascas piezas de rocas locales cuyos subtipos no están representados entre los instrumentos desechados en el sitio y piezas de rocas de procedencia indeterminada tampoco representadas entre 


\begin{tabular}{|l|c|c|c|c|c|c|c|c|c|c|c|c|}
\hline \multirow{2}{*}{} & \multicolumn{2}{|c|}{ C-V } & \multicolumn{2}{c|}{ C-IV } & \multicolumn{2}{c|}{ CJ-Z } & \multicolumn{2}{c|}{ C-III } & \multicolumn{2}{c|}{ C-II } & \multicolumn{2}{c|}{ C-I } \\
\cline { 2 - 12 } & A & B & A & B & A & B & A & B & A & B & A & B \\
\hline ARQ-C15 & 18 & 2 & 71 & 1 & - & - & 129 & 1 & 19 & 1 & 42 & 1 \\
ARQ-C14 & 13 & 1 & 41 & 1 & - & - & 54 & 1 & 9 & - & 47 & 1 \\
P.B/G.Z & 7 & - & 60 & 2 & 5 & - & 215 & 2 & 23 & 1 & 154 & 1 \\
Potrerillos A & 1.359 & 5 & 4.788 & 12 & 169 & 1 & 1.616 & 20 & 181 & 2 & 412 & 24 \\
Amarillos & 18 & - & 509 & 3 & 5 & - & 1.169 & 8 & 266 & - & 168 & 3 \\
Taguas & - & - & 30 & - & 5 & - & 42 & 1 & 38 & - & 14 & 1 \\
Locales NP & 389 & 4 & 1.204 & 4 & 16 & - & 588 & 6 & 67 & - & 308 & 15 \\
Indeterminadas & 77 & - & 334 & 4 & 19 & - & 863 & 4 & 77 & 2 & 587 & 5 \\
\hline Total & $\mathbf{1 . 8 8 1}$ & $\mathbf{1 2}$ & $\mathbf{7 . 0 3 7}$ & $\mathbf{2 7}$ & $\mathbf{2 1 9}$ & $\mathbf{1}$ & $\mathbf{4 . 6 7 6}$ & $\mathbf{4 3}$ & $\mathbf{6 8 0}$ & $\mathbf{6}$ & $\mathbf{1 . 7 3 2}$ & $\mathbf{5 2}$ \\
\hline
\end{tabular}

Tabla 3. Procedencia de materias primas. Referencias: A) totalidad del conjunto lítico; $B$ ) instrumentos.

los instrumentos. De ello se infiere el transporte a otras locaciones de instrumentos confeccionados y/o mantenidos en el sitio.

En todos los registros el análisis de secuencias según procedencia de materias primas indica que las rocas de fuentes con mayores costos de adquisición (ARQ-C15, ARQ-C14 y P.B/G.Z) están menos representadas en etapas iniciales que los recursos de fuentes con costos menores (Potrerillos A, Amarillos). En los componentes más tardíos las secuencias reductivas se hacen más extensas y las actividades de talla se diversifican en todos los casos.

\section{Análisis de artefactos}

En el registro lítico de C-V los instrumentos $(\mathrm{n}=12)$ tienen baja representación $(0,6 \%)$. Hay nueve tipos generales (Tabla 4) y 11 subtipos, la media de subgrupos tipológicos es 1,2 (Figura 3). Así la diversidad artefactual es baja en comparación el resto de los componentes. Se registran rocas locales NP y de tres fuentes locales (Figura 3), con el predominio de Potrerillos (Tabla 3). Esto evidencia una explotación poco diversificada de los recursos líticos. La variabilidad de filos es reducida y es la segunda más baja de la secuencia (Figura 3). Predominan filos con ángulos rasantes y oblicuos (Tabla 5), muy efectivos para tareas de corte (Andrefsky, 1998). Los filos abruptos, óptimos para trabajos de raspado, son casi inexistentes en este registro. No obstante, este tipo de actividad podría tener una mayor representación ya que estudios sobre huellas de uso efectuados en otras regiones indican que filos cercanos a los $60^{\circ}$ también son útiles para realizar movimientos transversales (Cueto, 2013). Casi la mitad de los instrumentos fueron confeccionados mediante trabajo no invasivo unifacial (Figura 4). La reducción y adelgazamiento bifacial se utilizó para la elaboración de puntas de proyectil y bifaces. Por tanto la inversión de trabajo en la manufactura de instrumentos fue mayoritariamente baja (Figura 5). Respecto de puntas de proyectil se registran dos piezas: 1- apedunculada, sub-triangular, mediano pequeña, elaborada en roca silícea procedente de Potrerillos A (Marsh et al., 2016, p. 72), 2- confeccionada sobre roca silícea de la fuente ARQ-C14, presenta en el extremo distal una burinación de impacto, diagnóstica del uso de la pieza en actividades de caza y en el extremo basal una fractura perversa vinculada al proceso de manufactura (Weitzel, Flegenheimer, Colombo y Martinez, 2014). Ambas piezas presentan evidencias de tareas de mantenimiento y reciclaje (Castro, 2015).

En C-IV los instrumentos $(\mathrm{n}=27)$ tienen menor representación en el conjunto lítico (0,4\%). Se registran 11 tipos generales (Tabla 4) y 19 subtipos, la media de 


\begin{tabular}{|l|c|c|c|c|c|}
\hline Tipos generales & C-V & C-IV & C-III & C-II & C-I \\
\hline Filo natural con rastros complementarios & 2 & 1 & 3 & 2 & 5 \\
Artefacto de formatización sumaria & - & 1 & 6 & - & 4 \\
Muesca de lascado simple & 1 & 1 & - & - & 2 \\
Muesca retocada & - & 1 & 1 & - & - \\
Filo en bisel asimétrico oblicuo/abrupto & 1 & 1 & - & 1 & 1 \\
Cuchillo de filo retocado & 1 & 3 & 5 & - & 4 \\
Denticulado, bisel oblicuo/abrupto, sección asimétrica & 2 & 4 & 6 & 2 & 14 \\
Artefacto mediano pequeño. R.B.O. Sección asimétrica. & - & - & 1 & - & 1 \\
Raspador & 1 & 2 & 2 & 1 & 1 \\
Raedera & - & - & 1 & - & 2 \\
Perforador & - & - & - & - & 3 \\
Unifacial & 1 & 2 & 2 & - & 1 \\
Bifaz & 1 & 7 & 5 & - & - \\
Punta de proyectil & 2 & 2 & 3 & - & 8 \\
Yunque & - & - & - & - & 1 \\
Art. manuf. por picado, abrasión, pulido & - & - & 1 & - & 1 \\
Fragmento de filo & - & - & 1 & - & - \\
Fragmento no diferenciado & - & 2 & 6 & - & 4 \\
\hline Total & 12 & 27 & 43 & 6 & 52 \\
\hline
\end{tabular}

Tabla 4. Tipos morfológicos de instrumentos.

\begin{tabular}{|l|c|c|c|c|c|}
\hline & C-V & C-IV & C-III & C-II & C-I \\
\hline Rasante $30^{\circ}$ & 6 & 1 & 8 & - & 8 \\
Muy oblicuo $\left(30^{\circ}-49^{\circ}\right)$ & - & 8 & 15 & 2 & 16 \\
Oblicuo $\left(50^{\circ}-79^{\circ}\right)$ & 5 & 14 & 17 & 4 & 19 \\
Abrupto $\left(80^{\circ}-99^{\circ}\right)$ & 1 & - & 1 & - & 2 \\
Obtuso $\left(100^{\circ}\right)$ & - & 2 & - & - & - \\
\hline
\end{tabular}

Tabla 5. Tipos de ángulos de filos activos en instrumentos.

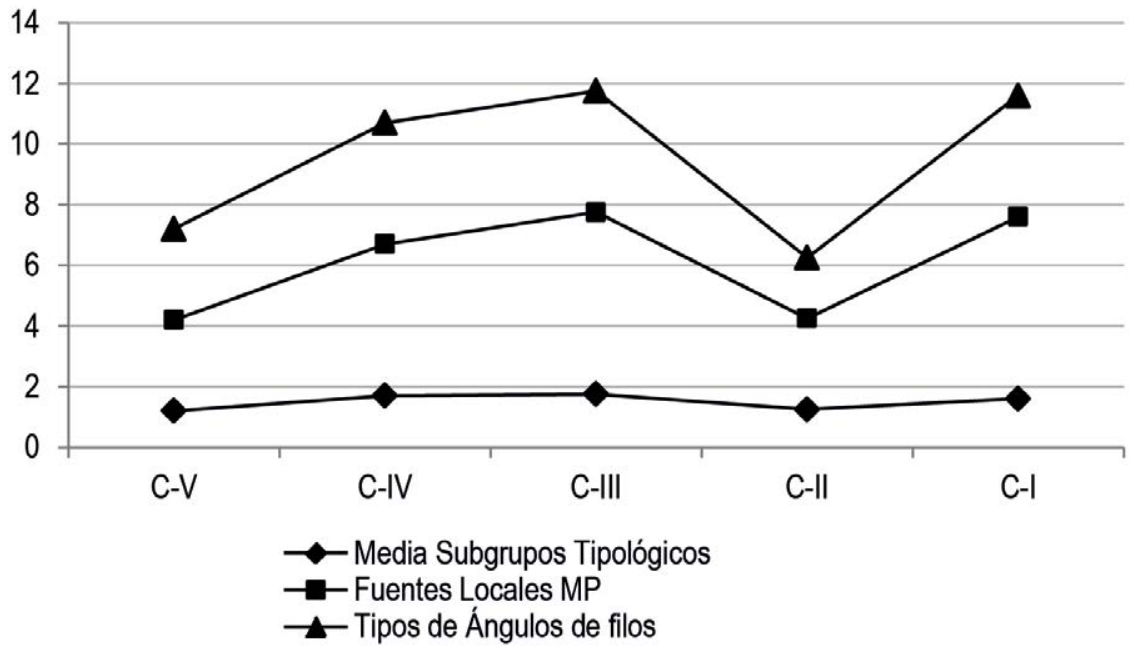

Figura 3. Diversidad artefactual. 


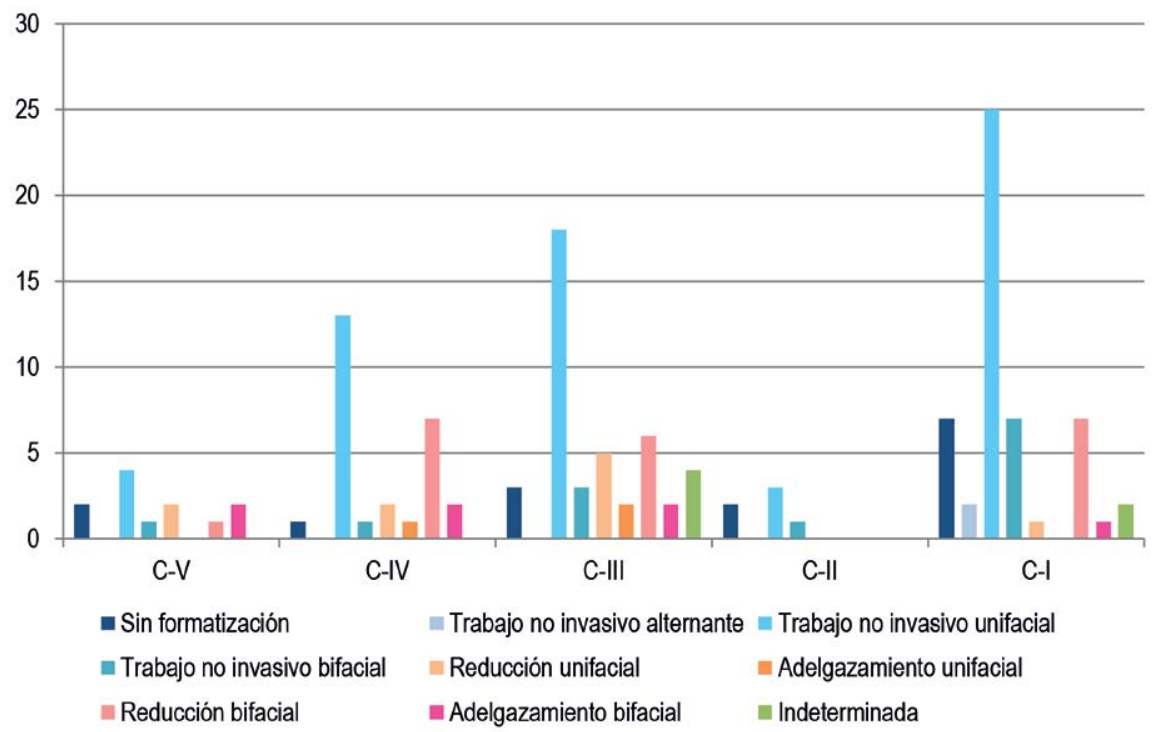

Figura 4. Frecuencia de clases técnicas en instrumentos.

subgrupos tipológicos es 1,7 (Figura 3). Por tanto, aumenta la diversidad tipológica. Se incrementan los bifaces cuya frecuencia es la mayor registrada en el sitio, las puntas de proyectil mantienen la misma frecuencia que en $\mathrm{C}-\mathrm{V}$ (Tabla 4). Las materias primas corresponden a cinco fuentes locales, a recursos locales NP y de procedencia indeterminada (Figura 3, Tabla 3). Esto indica una mayor diversificación de la procedencia de los recursos que podría estar vinculada a la ampliación de los rangos de adquisición de materias primas y la extensión de los circuitos anuales de movilidad. En cuanto a los filos, se observa un aumento en la variabilidad de ángulos (Figura 3), continúan predominando filos oblicuos, muy oblicuos y rasantes y, aunque en baja proporción, se registran ángulos obtusos (Tabla 5). El trabajo no invasivo unifacial continúa siendo la técnica de talla principal, la frecuencia de piezas con reducción bifacial se incrementa y se mantiene la de aquellas con adelgazamiento bifacial (Figura 4). En consecuencia, predominan piezas con baja inversión de trabajo y se incrementa la representación de instrumentos con alta inversión de trabajo (Figura 5). Estas opciones tecnológicas se aplican exclusivamente para la elaboración de bifaces y puntas de proyectil. Respecto a estas últimas se registran dos piezas: 1preforma apedunculada, elíptica, mediano grande y elaborada en cuarzo lechoso de procedencia indeterminada y 2 - punta apedunculada, triangular, mediano pequeña, sobre roca silícea de procedencia indeterminada (Marsh et al., 2016, p. 72).

En CJ-Z se registró un denticulado, con filo oblicuo, realizado sobre roca procedente de Potrerillos A y en estado de conservación entero. En CJ-Z el único instrumento ha sido escasamente formatizado y presenta un valor inversión de trabajo bajo.

En C-III los instrumentos $(\mathrm{n}=43)$ incrementan su representación en el conjunto lítico (1\%). Se identifican 12 tipos generales (Tabla 4) y 21 subtipos, la media de subgrupos tipológicos es 1,75 (Figura 3). La diversidad artefactual es similar a la del componente anterior. Se registra una pequeña disminución en la frecuencia de bifaces $y$ un leve incremento en la cantidad de puntas de proyectil (Tabla 4). Se incorpora un artefacto manufacturado por picado-abrasión-pulido: gran bloque rodado de riolita de procedencia local NP con marcas de piqueteo, tizne y sustancias adheridas que le otorgan una coloración rojiza. Su ingreso al sitio respondería a la necesidad de cumplimentar alguna función específica y habría sido trasladado a esta unidad como parte de un equipamiento (Cortegoso, 2014). Se registra por primera vez el uso de 


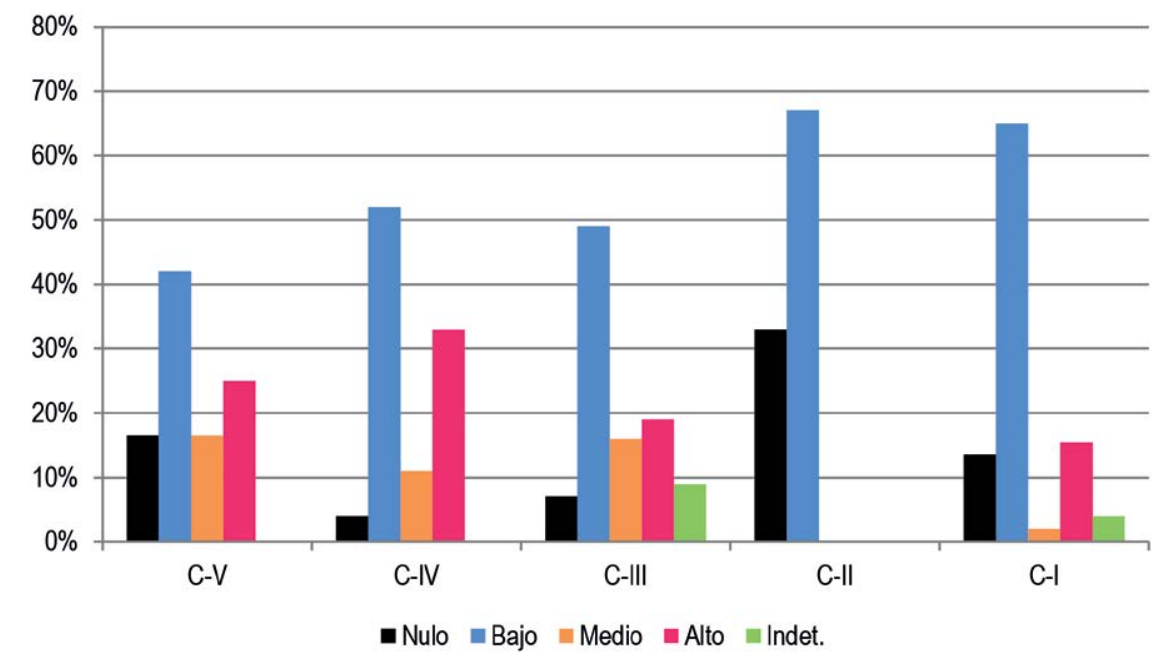

Figura 5. Inversión de trabajo en la manufactura de instrumentos.

las seis fuentes locales (Figura 3). Crece la representación de Potrerillos A, Amarillos y locales NP y se agregan recursos de Taguas (Tabla 3). La variedad de ángulos de filos $^{6}$ es similar a la de C-IV (Figura 3). Predominan filos con ángulos oblicuos, muy oblicuos y rasantes (Tabla 5), lo que podría indicar tareas de corte o aserrado. Además se registran filos abruptos. Aunque la representación de estos es baja, su presencia y la de ángulos oblicuos puede indicar un incremento de tareas de raspado y/o descortezamiento. Con respecto a las clases técnicas siguen predominando piezas con trabajo no invasivo unifacial (Figura 4), aunque la representación de piezas con baja inversión de trabajo disminuye levemente y se incrementa la de instrumentos sin formatización y con valores medios de inversión de trabajo (adelgazamiento y reducción unifacial) (Figura 5). Si bien es mayor la representación de piezas con alta inversión de trabajo (Figura 5), la frecuencia de elementos con adelgazamiento y reducción bifacial es similar a lo registrado en C-IV (Figura 4). La reducción bifacial se registra tanto en bifaces como en puntas mientras que el adelgazamiento bifacial sólo se registra en puntas de proyectil. Esto difiere de lo observado en los conjuntos previos donde ambas clases técnicas se registran en los dos tipos artefactuales. En este conjunto se hallaron tres puntas de proyectil: 1- con pedúnculo esbozado, forma pentagonal, mediano pequeña y confeccionada en roca silícea de Potrerillos A, 2- apedunculada, cordiforme, mediano pequeña, realizada en cuarzo cristalino de procedencia indeterminada y 3 - apedunculada, amigdaloide, grande, sobre roca silicificada de procedencia indeterminada (Marsh et al., 2016, p. 72). Las tres piezas poseen indicadores de tareas de reciclado.

En C-II los instrumentos $(\mathrm{n}=6)$ mantienen la misma representación en el conjunto lítico (1\%), pero sólo se identifican 4 tipos generales (Tabla 4) y 5 subtipos, con una media de subgrupos tipológicos de 1,25 (Figura 3). La diversidad tipológica es inferior a la del componente previo y similar a la del conjunto más temprano del sitio. Se destaca la ausencia de puntas de proyectil, bifaces y equipamiento de sitio (Tabla 4). La procedencia de los recursos es menos diversa, incluso menor a la registrada en $\mathrm{C}-\mathrm{V}$, ya que sólo están representadas tres fuentes locales y recursos de procedencia indeterminada (Figura 3, Tabla 3). La diversidad de ángulos de filos es la más baja de la secuencia (Figura 3). Sólo se registran ángulos muy oblicuos y oblicuos (Tabla 5), de lo que se deduce una caída en la variedad de tareas desarrolladas. Sólo se registran piezas sin formatización y con trabajo no invasivo unifacial y bifacial (Figura 4), la inversión de trabajo en la manufactura es la más baja del sitio (Figura 5).
6. No se incluye el fragmento de filo y el equipamiento de sitio. 
7. No se incluye: implemento de sitio, yunque, perforadores, fragmento de limbo.
En C-I los instrumentos $(\mathrm{n}=52)$ tienen la representación más alta de toda la secuencia (3\%), se registran 14 tipos generales (Tabla 4) y 23 subtipos, con una media de subgrupos tipológicos de 1,6 (Figura 3). Esto indica una diversidad tipológica similar a la de C-III y un incremento respecto a la de C-II. Se destaca la ausencia de bifaces, la presencia de nuevos tipos artefactuales (perforador y yunque), el incremento de puntas de proyectil (aunque cuatro de las piezas son fragmentos) y el registro nuevamente de un artefacto manufacturado por picado-abrasión-pulido (Tabla 4). Este instrumento está confeccionado sobre una plaqueta de gran tamaño de riolita local NP y presenta lustre, tizne, manchas de tonalidad ocre y hoyuelos. Se desconoce su uso, pero debido a su tamaño y peso habría permanecido en el lugar como equipamiento de sitio. Se diversifica la explotación de recursos para la confección de instrumentos (Figura 3). Se utilizan rocas procedentes de todas las fuentes locales, de fuentes locales NP y de procedencia indeterminada (Tabla 3). La variedad de ángulos de filo7 se incrementa y es similar a la de C-III (Figura 3), con un predominio de ángulos oblicuos, muy oblicuos y rasantes y una representación baja de ángulos abruptos (Tabla 5). La mayoría de los instrumentos presentan nula o escasa formatización (trabajo no invasivo unifacial y bifacial) (Figura 4). La representación de valores altos de inversión de trabajo es una de las menores del sitio (Figura 5). Estas características denotan una continuidad de la tendencia iniciada en C-III hacia una menor inversión de trabajo en la manufactura de instrumentos. Los valores altos corresponden casi exclusivamente a puntas de proyectil con predominio de reducción bifacial, sólo una punta presenta adelgazamiento bifacial. Las puntas de proyectil de este conjunto son: 1- apedunculada, amigdaloide, mediano pequeña, en roca silícea de procedencia indeterminada, con una burinación de impacto (sensu Weitzel et al., 2014), 2- apedunculada, triangular, mediano pequeña, en roca silícea de Potrerillos A, 3-apedunculada, triangular, mediano grande, en roca silícea de procedencia local NP, 4- apedunculada, oval, pequeña, en roca silícea de procedencia indeterminada.

\section{Discusión y conclusiones}

Los resultados del análisis lítico indican que el uso del alero y la explotación de este ambiente cordillerano variaron a través del tiempo. Estudios previos han indicado que los cambios en la intensidad de uso del sitio estarían vinculados, por un lado, a fluctuaciones ambientales ocurridas durante el Holoceno que afectaron la disponibilidad hídrica en la vertiente occidental de la cordillera (Cortegoso, 2014; Marsh et al., 2016). Conjuntamente la incorporación de actividades económicas productivas hacia fines del Holoceno medio habría incidido sobre la modalidad de uso del sitio, las estrategias de movilidad y la organización tecnológica de los grupos (Castro et al., 2013).

La retracción de los glaciares en ambientes de altura, registrada para el Holoceno temprano, permitió el desarrollo de micro-climas con recursos abundantes. La ocupación inicial de ARQ-18 se inicia ca. 9000 años AP, mil años después de finalizada la deglaciación (Zech, Kull y Veit, 2006). La llegada de los primeros grupos al valle del Taguas habría dependido de la variación en la disponibilidad hídrica en la ladera oeste de los Andes y no tanto de la presencia/ausencia de hielo. En función de la presencia en $\mathrm{C}-\mathrm{V}$ de ARQ-18 de puntas triangulares semejantes al diseño Tuina se propuso la posibilidad que el sitio fuera ocupado inicialmente por gente proveniente de las tierras altas del Norte y no de la costa pacífica (Marsh et al., 2016). Esto pudo ser efectivo debido a la similitud de los ambientes y la disponibilidad de camélidos. Un estudio macro-regional que evalúa la ocupación durante el Holoceno medio en áreas cordilleranas y planicies de Argentina y Chile, indicó que cuando la aridez comenzó a incrementarse a inicios de este período los sistemas de movilidad se reconfiguraron y los grupos se instalaron en espacios cordilleranos que contaban con mayores recursos hídricos que los valles y llanuras de ambas vertientes andinas 
(Méndez et al., 2015). En este contexto, el valle del Taguas pudo ser explotado por grupos provenientes de diferentes regiones con sistemas de alta movilidad residencial. En ARQ-18 el registro lítico de C-IV evidencia la mayor intensidad ocupacional de toda la secuencia, lo cual puede deberse al incremento del uso de estos ambientes de altura (Cortegoso, 2014; Marsh et al., 2016). Durante el período de hiperaridez del Holoceno medio los circuitos de movilidad se habrían reorientado nuevamente hacia espacios con concentración de recursos (Grosjean, Santoro, Thompson, Núñez y Standen, 2007; Yacobaccio et al., 2013; entre otros). Coherente con este escenario es la sincronía entre las primeras centurias del hiato registrado en ARQ-18 y la ausencia de ocupación humana en las zonas bajas de ambas laderas andinas, entre los $29^{\circ}-35^{\circ} \mathrm{S}$, que finaliza hacia los 6300 y 6000 años cal AP respectivamente (Méndez et al., 2015). Es posible que la disminución de espacios bajos con disponibilidad de recursos en una amplia franja latitudinal obligara a los grupos a migrar a otras regiones quedando el valle del Taguas muy alejado de las bases residenciales invernales (Castro et al., 2013; Cortegoso, 2014; Marsh et al., 2016). Hacia fines del Holoceno medio si bien se incrementó la humedad, las condiciones ambientales se volvieron menos estables y esto pudo ser un factor significativo en la incorporación del pastoralismo a nivel macro-regional (Morales et al., 2009). En el Norte Semiárido de Chile a finales del Holoceno medio y principios del tardío ( $c a$. 5000-3700 años AP) se registra una nueva fase de incremento de la aridez en los valles y un aumento de la humedad en los sectores altos (Veit, 1996), condiciones que alentaron la reocupación de la cordillera (Méndez et al., 2015). Durante esta fase ARQ-18 fue reocupado por grupos que habrían iniciado una diversificación en la subsistencia (Castro et al., 2013; Cortegoso, 2014; Marsh et al., 2016). Para los primeros mil años del Holoceno tardío en los valles del Norte Semiárido Chileno hay evidencias de condiciones ambientales más húmedas (ca. 4000-3000 años AP) que afectaron de manera negativa la ocupación de espacios cordilleranos y alentaron las ocupaciones de ambientes más bajos en la vertiente occidental andina (Méndez et al., 2015). De manera sincrónica en ARQ-18 se registra el C-II con una caída en la intensidad ocupacional. Un nuevo incremento de las condiciones áridas en la vertiente occidental de los Andes (ca. 3000-1800 años AP) (Veit, 1996) habría resultado nuevamente en un uso más intenso de los sectores de altura (Méndez et al., 2015). El C-I de ARQ-18 tiene una alta correlación con esta fase.

Como se verá a continuación los resultados del análisis lítico del sitio refuerzan estas propuestas y señalan cambios en la intensidad de talla, la explotación de recursos y la organización tecnológica vinculados a los cambios en la duración y recurrencia de las estadías, la movilidad y las estrategias de subsistencia de los grupos.

El registro lítico del C-V (ca. 8900-8000 años AP) se caracteriza por el volumen reducido de piezas, baja $d$ y NMGE c/100 años, uso predominante de recursos locales concentrado en la explotación de algunas de las fuentes detectadas en el área. La representación en estadios avanzados de la secuencia reductiva de fuentes ubicadas en el sector de mayor altitud y de secuencias más amplias de las fuentes de sectores intermedios y bajos evidencia sistemas de producción lítica secuenciales y regionales (sensu Ericson, 1984). Las tareas de talla se concentraron en la formatización de instrumentos, algunos de los cuales fueron descartados en el sitio mientras otros fueron transportados. También se observaron desechos de instrumentos que probablemente ingresaron al sitio como parte de toolkits, se utilizaron, se mantuvieron y volvieron a transportarse. La diversidad artefactual es baja, predominan filos agudos que pudieron utilizarse en actividades de corte y en menor medida se registran filos más abruptos vinculados a tareas de raspado (sensu Andrefsky, 1998). Las piezas confeccionadas mediante reducción y adelgazamiento bifacial (puntas de proyectil y bifaces) presentan diseños confiables, mantenibles y transportables (sensu Bleed, 1986). La práctica de la caza está evidenciada por la presencia de dos puntas de proyectil, una de las cuales presenta una fractura de 
impacto. La morfología de una de estas piezas (triangular pequeña) es similar al diseño de puntas Tuina halladas en sitios de la Puna de Argentina y Chile con cronologías tempranas entre 11000 y 8500 años AP, vinculadas al uso de propulsor y a la caza en espacios abiertos por cazadores moviéndose de manera individual a través de largas distancias (Hocsman, Martínez, Aschero y Calisaya, 2012; Martinez, 2007; Núñez, Grosjean y Cartagena, 2002; entre otros). La distribución y cronología de estas puntas está en debate (Grosjean et al., 2005) y las piezas de ARQ-18 pueden representar la dispersión más meridional y tardía del tipo Tuina.

En cuanto a la organización de la tecnología, las características del registro indican la implementación de estrategias conservadas, expeditivas y oportunísticas (sensu Nelson, 1991). La estrategia de conservación estaría relacionada fundamentalmente a la alta movilidad y al riesgo vinculado a la subsistencia basada en la caza-recolección. La mayor inversión de trabajo en la formatización de piezas relacionadas directamente con la adquisición de recursos móviles (puntas de proyectil), la elaboración de instrumentos con diseños mantenibles y transportables (bifaces), el mantenimiento y reciclaje de artefactos con alta inversión de trabajo (puntas de proyectil), señalan la práctica de este tipo de plan tecnológico. Dentro de este tipo de estrategia también se rescata la presencia de rocas de procedencia indeterminada cuyo descarte en el sitio puede ser el resultado del mantenimiento de toolkits provenientes de otras áreas. Por otro lado el descarte de piezas enteras, con baja inversión de trabajo y confeccionadas sobre recursos localmente disponibles permite inferir planes tecnológicos expeditivos. Finalmente, la presencia de filos naturales con rastros complementarios en rocas locales indica el uso de materiales disponibles de manera oportunística.

Este conjunto es característico de un campamento temporario, con permanencias cortas, utilizado para el desarrollo de un rango acotado de actividades por grupos con alta movilidad residencial (Andrefsky, 1998; Kent, 1992; Kuhn, 2004; Shott, 1986; Torrence, 1983, 1989). Como respuesta a la alta movilidad y al riesgo a corto plazo derivado de la caza-recolección se desarrollaron estrategias tecnológicas conservadas. También se implementaron estrategias oportunísticas y expeditivas, puestas en práctica una vez obtenido el conocimiento sobre la disponibilidad de recursos en el área y la posibilidad de anticipar las tareas a desarrollar, característicos del avance de la colonización (Franco, 2004). La presencia en el registro del C-V de ARQ-18 de puntas de proyectil semejantes al tipo Tuina orienta a pensar que los primeros habitantes del área pudieron proceder de espacios puneños.

En C-IV (ca. 7300-6700 años AP) el registro lítico es el más abundante de toda la secuencia y presenta la mayor $d$ y NMGE c/100 años, a pesar de su menor duración y de poseer una capa estratigráfica menos espesa. Se diversifica la explotación de los recursos y se explotan todas las fuentes disponibles. Estas características han sido registradas también en sitios de la Puna argentina con cronologías semejantes a las de este componente (como Quebrada Seca 3 y Cueva Salamanca 1) y se las ha interpretado como el resultado de agregación de bandas en espacios con abundancia de recursos ocupados más intensivamente tanto en duración como en recurrencia (Pintar, 2004). En ARQ-18 a las características mencionadas se le agregan la mayor variabilidad artefactual y el aumento de actividades de talla orientadas a la búsqueda de soportes que podrían ser el resultado de una mayor intensidad de uso del sitio en tiempo y/o cantidad de individuos.

Se mantienen sistemas de producción lítica secuenciales. Se elaboran instrumentos, algunos descartados en el sitio y otros transportados, y se mantienen instrumentos que probablemente ingresaron como parte de toolkits. Entre los instrumentos descartados in situ se destacan piezas con baja inversión de trabajo en la manufactura y elaboradas sobre recursos locales. Entre las piezas con alta inversión de trabajo aumentan los bifaces 
cuyos diseños flexibles y versátiles se vinculan a sistemas de alta movilidad (sensu Bleed, 1986; Kelly, 1988). El incremento en la variabilidad artefactual y de ángulos de filos permite inferir el desarrollo de una mayor gama de tareas. Posiblemente se mantuvieron actividades de corte y se incrementaron tareas de raspado, las cuales requieren de más tiempo para su desarrollo (Franco, 2004; Marchione y Bellelli, 2013). La continuidad de la caza está evidenciada por la presencia de una punta de proyectil y una preforma de punta. El diseño triangular apedunculado de la primera difiere de los tipos registrados en la macro-región para esta cronología (Gambier, 2000; Méndez y Jackson, 2008; entre otros) y se asemeja al de las piezas del componente más temprano del sitio.

El sitio continuó siendo utilizado como un campamento semipermanente donde se realizaban tareas derivadas de la caza, pero con ocupaciones de mayor intensidad y/o quizás llevadas a cabo por grupos más numerosos, como se ha propuesto en áreas próximas. Debido a la continuidad de dicha actividad económica y de sistemas de alta movilidad se mantuvieron estrategias conservadas que aseguran que las herramientas estén disponibles cuando son necesarias, mientras que las estadías más extensas y recurrentes y el amplio conocimiento del área alentaron el desarrollo de planes expeditivos y oportunísticos (Franco, 2004; Nelson, 1991; Parry y Kelly, 1987; Torrence, 1983).

Posterior a C-IV se registra una disrupción en el uso del sitio de 1600 años aproximadamente ( $c a .6700$ y 5100 años AP) evidenciada por la escasa sedimentación, la ausencia de material orgánico y el reducido registro lítico que conforma el CJ-Z. El análisis de este material indicó una caída abrupta en la $d$ y NMGE c/100 años. Se incrementa la representación de rocas de procedencia indeterminada y la explotación de rocas locales se limita a las de menor costo de adquisición y con las mejores calidades para la talla (Potrerillos A y Amarillos). Las actividades de talla se restringen a la formatización de instrumentos que se transportan. Es posible que este registro sea producto de procesos mecánicos de migraciones de material del componente inmediatamente superior ya que se trata de micro y ultramicrolascas de las mismas materias primas que estas piezas presentan en C-III. Sin embargo, las características mencionadas podrían ser el resultado de ocupaciones efímeras y discontinuas del sitio por parte de grupos pequeños que ampliaron sus rangos de movilidad.

La reocupación del sitio está registrada en el C-III (ca. 5100 y 4300 años AP) a partir del cual ARQ-18 presenta evidencias que lo vinculan a sociedades con economías diversificadas. La posible introducción de animales domésticos en esta fracción temporal se sustenta no sólo en la presencia del morfotipo Lama glama en el registro óseo (Gasco, 2014) sino también en la configuración de espacios internos acondicionados, el mantenimiento de fogones con excretas de camélidos, la presencia de instrumentos de textilería y de equipamiento de sitio (Castro et al., 2013; Cortegoso, 2014; Durán y Cortegoso, 2008).

En este componente el incremento en el volumen de material, en la $d$ y en el NMGE c/100 años denota ocupaciones relativamente intensivas, con un aumento en la recurrencia del uso del sitio. Predomina el uso de rocas locales, se diversifica el uso de fuentes y aumenta el uso de Amarillos. Los sistemas de producción lítica continúan siendo secuenciales. La explotación de rocas de procedencia indeterminada se incrementa, cuyas fuentes potenciales se hallarían en la ladera occidental de los Andes. Esto respondería a la incorporación del sitio a circuitos periódicos de trashumancia de grupos que explotarían el área a partir del Holoceno medio final.

En esta fracción temporal se incrementan las tareas de producción de instrumentos y el descarte de los mismos, entre los cuales aumentan las piezas con baja inversión de trabajo y elaboradas sobre rocas locales. Los análisis de secuencias reductivas y clases técnicas evidencian que la talla bifacial continuó implementándose con una 
intensidad semejante a la registrada en componentes previos. Indicador de ello es la similitud en la representación de lascas de adelagazamiento bifacial y en la frecuencia de instrumentos con alta inversión de trabajo (puntas y bifaces). El cambio se observa en el uso del adelgazamiento bifacial, técnica de talla que en adelante sólo se registra en puntas de proyectil. La diversidad artefactual aumenta posiblemente vinculada a una mayor variedad de actividades y una posible reducción en la movilidad residencial (sensu Olivera, 2001; Shott, 1986). La continuidad de ciertos grupos tipológicos estaría relacionada a "funciones primarias" (sensu Aschero, 1975) de carácter básico que se desarrollan más allá de la actividad económica predominante (sensu Hocsman, 2014), por ejemplo el desposte y procesamiento de animales, descuartizamiento de presas, trabajo de pieles y cueros, talla y confección de herramientas líticas. El registro de nuevos grupos tipológicos puede responder a nuevas exigencias derivadas de la extensión y periodicidad de las estadías y la incorporación de actividades de producción de alimentos. Entre los nuevos tipos de instrumentos se destaca una pieza que sería parte del equipamiento del sitio. Además, se registraron carporrestos (Geoffroea decorticants y Prosopis sp.) con marcas antrópicas que pudieron ser generadas al ser golpeadas contra el suelo o con alguna roca (Llano y Fernández, 2014). La realización de esta actividad en el sitio podrá ser evaluada con estudios funcionales específicos sobre dichas piezas líticas. La presencia de puntas de proyectil revela que la actividad de caza se mantuvo. Estas piezas presentan mayor variabilidad de diseño y evidencias de reciclado. La punta apedunculada con contorno amigdaloide es semejante a algunas puntas Morrillos de San Juan con cronologías entre ca. 8000 y 4000 años AP (Gambier, 2000) y presenta evidencias de reciclado que permiten pensar en un comportamiento de reclamación del artefacto (sensu Schiffer, 1987).

Estos datos manifiestan un predominio de estrategias expeditivas. Las estrategias conservadas se redujeron y se limitaron a la confección de instrumentos vinculados a la caza. Tanto los planes expeditivos como los conservados son esperables cuando los grupos anticipan ocupaciones largas (sensu Kent, 1992) y mantienen circuitos de movilidad repetidos y predecibles (sensu Tomka, 1993). Los cambios del registro de C-III podrían ser el resultado del uso del sitio por grupos transicionales con circuitos periódicos de movilidad, con menor movilidad residencial, que realizaban una mayor variedad de actividades y permanecían durante estadías más largas en el sitio. Como se mencionó al inicio del trabajo, existen contextos en el Noroeste Argentino que presentan cronología y conjuntos líticos similares al del C-III de ARQ-18 y que han sido relacionados a un proceso de transición hacia la domesticación de camélidos (Aschero y Hocsman, 2011; Escola, 1996, 2000; Hocsman, 2014; Yacobaccio, 2006).

En C-II ( $c a .3700$ años AP) el volumen de material es el más reducido de toda la secuencia de ocupación del sitio. La menor representación de rocas de procedencia indeterminada implica un menor transporte hacia el sitio de instrumentos sobre materias primas que, según se indicó, podrían ser procedentes de la vertiente occidental. La mayor explotación de la fuente Amarillos, tendencia que se insinúa en el componente anterior, podría indicar que dentro del área la movilidad estaría más acotada al sitio. Sumando a esta información la proveniente de otros emplazamientos de la región de estudio con cronologías del Holoceno tardío (Lucero, 2015), se ha propuesto una explotación preferencial de los espacios ubicados en el norte de la región que pudo deberse a la mayor concentración de recursos bióticos (ríos, arroyos, grandes vegas y fauna) y a la presencia en este sector de una ruta de conexión con el Norte Semiárido Chileno (Lucero et al., 2017).

La evaluación de secuencias reductivas indicó la persistencia de sistemas de producción secuenciales, registrándose en el sitio un predominio de las tareas finales y una muy baja representación de las actividades iniciales. Los instrumentos son escasos. Hay un gran volumen de micro y ultramicrolascas de recursos locales no representados entre 
los instrumentos. Es posible que haya aumentado el transporte a otras locaciones de instrumentos producidos en el sitio. Sólo se registraron filos naturales con rastros complementarios y piezas con formatización restringida a los bordes, la reducción bifacial pierde visibilidad. Se reduce la diversidad artefactual y de ángulos de filos indicando la realización de tareas menos diversas. Todos los instrumentos presentan filos agudos que pueden relacionarse principalmente con tareas de corte o aserrado.

Las características de este registro evidencian ocupaciones de menor intensidad, más cortas y esporádicas, lo que alentó la implementación de estrategias tecnológicas expeditivas y oportunísticas. Este cambio en la modalidad de ocupación del sitio podría explicarse como una respuesta al incremento de la humedad en los valles del Norte Semiárido Chileno (Méndez et al., 2015). Este tipo de respuesta es parte de la flexibilidad de los sistemas trashumantes evaluados en espacios áridos y ecológicamente inestables comparables (Erazo y Garay-Flühmann, 2011).

El C-I de ARQ-18 (ca. 3000 y 1500 años AP) presenta un contexto similar al del C-III. Los conjuntos óseo y botánico evidencian el desarrollo de una amplia variedad de tareas que involucró la caza, el pastoreo y el aprovechamiento de plantas silvestres (Gasco, 2014; Llano y Fernández, 2014). El conjunto lítico es menos voluminoso y registra la menor $d$ y el menor NMGE c/100 años, sin embargo posee la mayor cantidad de instrumentos del sitio. La escasa inversión de trabajo en la formatización de instrumentos limitada al retoque de los bordes puede explicar el bajo volumen. Considerando la abundancia y diversidad de los registros óseo y botánico, la sedimentación y la extensión temporal, se deduce que el sitio fue ocupado con una intensidad semejante a la de C-III aunque, posiblemente, mediante estadías más prolongadas y con mayor redundancia.

Es más destacada la tendencia que señala cambios en la organización tecnológica. Los recursos de procedencia indeterminada alcanzan la mayor representación de toda la secuencia mientras que las rocas de procedencia local presentan el porcentaje más bajo. Los sistemas de producción lítica continúan siendo secuenciales, aunque se registraron secuencias reductivas más extensas y en algunos casos completas. La formatización de instrumentos se mantiene como la actividad de mayor desarrollo pero se incrementan las actividades iniciales y finales de la talla lítica, destacándose el registro de lascas de reactivación de filos por primera vez. La alta inversión de trabajo se registra casi exclusivamente en puntas de proyectil y prácticamente se limita a la reducción bifacial. El adelgazamiento bifacial sólo se aplicó en la formatización de una punta, lo cual implica una disminución en el tiempo y energía invertidos en la confección de estos artefactos (sensu Hocsman, 2014). La diversidad artefactual se incrementa. Los instrumentos registrados pueden relacionarse con una gran variedad de actividades posibles (caza, procesamiento de animales, trabajo de pieles y cueros, talla y confección de herramientas líticas) algunas de las cuales demandan estadías más prolongadas para su efectivo desarrollo. En este componente se registra también un soporte lítico de gran tamaño asimilable a un equipamiento de sitio. Todas estas características pueden vincularse a una reducción en la movilidad residencial (sensu Shott, 1986).

La presencia de puntas de proyectil indica la continuidad de la caza como actividad económica. En general se trata de puntas triangulares similares a las provenientes de contextos tardíos del Norte Semiárido Chileno correspondientes a grupos con economías mixtas (Méndez y Jackson, 2008). Algunas de estas piezas evidenciaron una reducción en sus tamaños en relación con las puntas del C-III. Esta disminución en las dimensiones se ha registrado en contextos de grupos de pastores plenos en la macro-región y su predominio ca. 3000 años AP ha sido relacionado en algunos casos al uso del arco y flecha (De Souza, 2004; Gambier, 2000; Hocsman, 2010; Méndez y Jackson, 2008). 
Nuevamente se registra un predominio de estrategias tecnológicas expeditivas y oportunísticas, relacionadas a la mayor intensidad y recurrencia en las ocupaciones del sitio y a la diversificación de las actividades económicas que habrían obligado a los individuos a distribuir el tiempo entre una mayor variedad de actividades. A pesar de la incorporación del pastoralismo a la subsistencia, la caza nunca dejó de practicarse y siempre se mantuvo como una actividad importante; esto explica la continuidad de estrategias conservadas. La presencia de puntas de proyectil con alta inversión de trabajo en su elaboración es una evidencia de ello. Se deduce, entonces, que el sitio pudo funcionar como un campamento semipermanente de grupos con una subsistencia diversificada.

Este estudio ha permitido detectar cambios en la organización tecnológica vinculados a modificaciones en las estrategias de subsistencia y en los patrones de movilidad de las sociedades que ocuparon el sitio. También se identificaron continuidades en la organización tecnológica, como es el mantenimiento de estrategias conservadas relacionadas a la tecnología de caza. Esta actividad fue una constante en la subsistencia de los grupos que habitaron el valle, aunque posiblemente su organización tecnológica (sensu Ratto, 2003) haya variado a través del tiempo. Al respecto se han iniciado estudios que se enfocan en los sistemas de armas, las técnicas y estrategias de caza implementados por grupos con economías diferentes.

La investigación desarrollada involucra una región con escasos antecedentes arqueológicos y una escala diacrónica amplia que incluye cambios en la base de la subsistencia, por tanto aporta información de interés para áreas arqueológicas importantes a uno y otro lado de los Andes.

\section{Agradecimientos}

Al Consejo Nacional de Investigaciones Científicas y Técnicas por el apoyo y financiamiento de las investigaciones. El trabajo presentado es resultado de una tesis doctoral dirigida por la Dra. Cortegoso, sus aportes y constante apoyo facilitaron el desarrollo de este estudio. Agradezco también a las Dras. Flegenheimer, Cattáneo y Franco quienes evaluaron la tesis doctoral, a los Dres. Hocsman y Nami y Weitzel quienes colaboraron en el estudio de puntas de proyectil y fracturas de instrumentos. Finalmente, agradezco a los evaluadores del presente trabajo cuyas sugerencias y correcciones permitieron mejorar y enriquecer la propuesta original. 


\section{Referencias citadas}

"Andrefsky, W. (1998). Lithics Macroscopic Approaches to Analysis. Cambridge: Cambridge University Press.

" Aschero, C. (1975). Ensayo para una clasificación morfológica de artefactos líticos. Informe a CONICET. Manuscrito inédito.

" Aschero, C. y Hocsman, S. (2004). Revisando cuestiones tipológicas en torno a la clasificación de artefactos bifaciales. En A. Acosta, D. Loponte y M. Ramos (Eds.), Temas de Arqueología, Análisis Lítico (pp. 7-25). Buenos Aires: Sociedad Argentina de Antropologia-Secretaría de Cultura de la Nación-Instituto Nacional de Antropología y Pensamiento Latinoamericano, Universidad Nacional de Luján.

"Aschero, C.yHocsman, S. (2011). Arqueología de las ocupaciones cazadoras-recolectoras de fines del Holoceno medio de Antofagasta de la Sierra (Puna Meridional Argentina). Chungara. Revista de Antropología Chilena, 43, 393-411.

" Binford, L. R. (1979). Organization and formation processes: looking at curated technologies. Journal of Anthropological Research, 35(3), 255-273.

" Bleed, P. (1986). The optimal design of hunting weapons: maintainability or reliability. American Antiquity, 51(4), 737-747.

"Castro, S. C. (2015). Explotación de recursos líticos durante el Holoceno en el límite de vertientes cordilleranas. Valle del río de Las Taguas, San Juan, Argentina. (Tesis Doctoral inédita), Universidad Nacional de Córdoba, Argentina.

» Castro, S. C., Gasco, A., Lucero, G. F. y Cortegoso, V. (2013). Mid-Holocene hunters and herders of southern cordillera, Northwestern Argentina. Quaternary International, 307, 96-104.

"Castro, S. C., Lucero, G. F., Cortegoso, V. y Winocur, D. (2014). Fuentes de aprovisionamiento de materia prima y sistemas de producción lítica en Los Andes (Noroeste de San Juan, Argentina). Relaciones de La Sociedad Argentina de Antropología, XXXIX(2), 365-386.

"Clarkson, C. (2008). Changing reduction intensity, settlement, and subsistence in Wardaman country, Northern Australia. En W. Andrefsky (Ed.), Lithic Technology (pp. 286-316). Nueva York: Cambridge University Press.

"Cortegoso, V. (2004). Organización Tecnológica: Explotación de recursos líticos y el cambio en la subsistencia de cazadores a agricultores en el N.O. de Mendoza. (Tesis Doctoral inédita), Universidad Nacional de La Plata, Argentina.

"Cortegoso, V. (2014). Valle de Las Taguas, ARQ-18. Estratigrafía, secuencia temporal y ocupaciones humanas. En V. Cortegoso, V. Durán y A. Gasco (Eds.), Arqueología de Ambientes de Altura de Mendoza y San Juan (Argentina) (pp. 209-242). Mendoza: EDIUNC.

»Cortegoso, V., Durán, V., Castro, S., Gasco, A., Lucero, G. y Winocur, D. (2012a). Human Occupation in the Northern Argentine-Chilean Central Andes during the Early Holocene. En L. Miotti, M. Salemme, N. Flegenheimer y T. Goebel (Eds.), Southbound, Late Pleistocene of Latin American, Spetial Edition Current Research in the Pleistocene (pp. 83-87). Texas: A\&M University.

》Cortegoso, V., Durán, V., Castro, S. y Winocur, D. (2012b). Disponibilidad de recursos líticos y explotación humana del límite de Los Andes, valle del río de Las Taguas, San Juan, Argentina. Chungara. Revista de Antropología Chilena, 44(1), 59-72. 
"Cueto, M. (2013). Estudio comparativo forma-función de artefactos líticos. Evidencias de las ocupaciones iniciales de la localidad arqueológica La María. En F. Zangrando, R. Barberena, A. Gil, G. Neme, M. Giardina, L. Luna, C. Otaola, S. Paulides, L. Salgán y A. Tivoli (Comps.), Tendencias Teórico-Metodológicas y Casos de Estudio en la Arqueologia de la Patagonia (pp. 325-334). Buenos Aires: Museo de Historia Natural de San Rafael, SAA, INAPL.

»De Souza, P. (2004). Tecnologías de proyectil durante los períodos Arcaico y Formativo en el Loa Superior (Norte de Chile) a partir del análisis de puntas líticas. Chungara. Revista de Antropología Chilena, 36, 61-76.

» Dibble, H. L. (1992). Local Raw Material Explotation and its Effects on Lower and Middle Paleolithic Assemblage Variability. Raw Material Economies among hunter-gatheres. Publications in Anthropology, 19, 33-47.

» Durán, V. y Cortegoso, V. (2008). Ocupaciones humanas en la cordillera del norte de San Juan: cambios en la subsistencia y la tecnología ósea durante el Holoceno. Trabajo presentado en el I Congreso Nacional de Zooarqueología Argentina, Malargue, Argentina.

» Erazo, M. y Garay-Flühmann, R. (2011). Tierras secas e identidad. Una aproximación cultural a las prácticas de subsistencia de las comunidades campesinas del semiárido. Provincia de Elqui, Chile. Revista de Geografía Norte Grande, 50, 45-61.

» Ericson, J. (1984). Toward the analysis of lithic production systems. En J. Ericson y B. Purdy (Eds.), Prehistoric Quarries and Lithic Production (pp. 1-9). Nueva York: Cambridge University Press.

»Escola, P. (1996). Riesgo e incertidumbre en economías agropastoriles: consideraciones teórico metodológicas. Arqueología, 6, 9-23.

»Escola, P. (2000). Tecnología lítica y sociedades agropastoriles tempranas. (Tesis Doctoral inédita), Universidad Nacional de Buenos Aires, Argentina.

» Franco, N. V. (2004). La organización tecnológica y el uso de escalas amplias. El caso del sur y oeste de Lago Argentino. En A. Acosta, D. Loponte y M. Ramos (Eds.), Temas de Arqueología, Análisis Lítico (pp. 101-144). Buenos Aires: Sociedad Argentina de Antropologia-Secretaría de Cultura de la Nación-Instituto Nacional de Antropologíay Pensamiento Latinoamericano, Universidad Nacional de Luján.

» Gambier, M. (2000). Prehistoria de San Juan. San Juan: Ansilta.

"Gasco, A. (2014). Las arqueofaunas del alero ARQ-18 (San Juan, Argentina): aprovechamiento de camélidos silvestres y domésticos durante el Holoceno medio y tardío. En V. Cortegoso, V. Durán y A. Gasco (Eds.), Arqueología de ambientes de altura de Mendoza y San Juan (Argentina) (pp. 171-202). Mendoza: EDIUNC.

» Gould, R. A. y Saggers, S. (1985). Lithic Procurement in Central Australia: A Closer Look at Binford's Idea of Embeddedness in Archaeology. American Antiquity, 50(1), 117-136.

» Grosjean, M., Núñez, L. y Cartajena, I. (2005). Palaeoindian occupation of the Atacama Desert, northern Chile. Journal of Quaternary Science, 20, 643-653.

» Grosjean, M., Santoro, C., Thompson, L., Núñez, L. y Standen, V. (2007). Mid-Holocene climate and culture change in the South Central Andes. En D. Anderson, K. A. Maasch y D. H. Sandweiss (Eds.), Climate Change and Cultural Dynamics. A global perspective on Mid-Holocene transitions (pp. 51-115). Estados Unidos: Elsevier.

» Hocsman, S. (2010). Cambios en las puntas de proyectil durante la transición de cazadores-recolectores a sociedades agro-pastoriles en Antofagasta de la Sierra (Puna Argentina). Arqueología, 16, 59-86. 
»Hocsman, S. (2014). Continuities and discontinuities in the process of transition to food production in Antofagasta de la Sierra (Southern Argentine Puna): the case of flaked stone tools. En E. Pintar (Ed.), Hunter-Gatherers from a High-Elevation Desert: People of the Salt Puna. Northwest Argentina (pp. 201-230). Oxford: BAR International Series.

» Hocsman, S. y P. Escola. (2006). Inversión de trabajo y diseño en contextos líticos agropastoriles (Antofagasta de la Sierra, Catamarca). Cuadernos del Instituto Nacional de Antropología y Pensamiento Latinoamericano, 21, 75-90.

» Hocsman, S., Martínez, J. G., Aschero, C. y Calisaya, A. (2012). Variability of Triangular NonStemmed Projectile Points ofEarly Hunter-Gatherers of the Argentinian Puna. En L. Miotti, M. Salemme, N. Flegenheimer y T. Goebel (Eds.), Southbound, Late Pleistocene of Latin American, Spetial Edition Current Research in the Pleistocene (pp. 64-67). Texas: A\&M University.

» Kelly, R. L. (1988). The three sides of a biface. American Antiquity, 53(4), 717-734.

»Kent, S. (1992). Studying Variability in the Archaeological Record: An Ethnoarchaeological Model for Distinguishing Mobility Patterns. American Antiquity, 57(4), 635-66o.

» Kuhn, S. L. (2004). Upper Palaeolithic raw material economies at Ucagizli cave, Turkey. Journal of Anthropological Archaeology, 23, 431-448.

»Llano, C. y J. Fernández. (2014). El entorno vegetal de las poblaciones humanas prehistóricas en el sitio ARQ- 18: análisis carpológico. En V. Cortegoso, V. Durán y A. Gasco (Eds.), Arqueología de Ambientes de Altura de Mendoza y San Juan (Argentina) (pp. 159-169). Mendoza: EDIUNC.

»Lucero, G. F. (2015). Biogeografía y Paleoecología humana de tierras altas: subsistencia y tecnología en el Valle del Río de las Taguas (Departamento de Iglesia, Provincia de San Juan). (Tesis Doctoral inédita), Universidad Nacional de Cuyo, Argentina.

» Lucero, G. F., Castro, S. C., Marsh, E. y Cortegoso, V. (2016). Costos de explotación de recursos líticos en ambientes de altura (NO de San Juan, Argentina). Una propuesta metodológica SIG. Trabajo presentado en XIX Congreso Nacional de Arqueología Argentina, Tucumán, Argentina.

» Lucero, G. F., Castro, S. C. y Cortegoso, V. (2017). Tecnologia lítica de cazadores y pastores andinos: cambios y continuidades en la explotación de recursos líticos durante el Holoceno en el NO de San Juan. Revista del Museo de Antropología 1o(suplemento especial 1), 65-74.

» Lucero, G. F., Marsh, E. y Castro, S. (2014). Rutas Prehistóricas en el NO de San Juan: una propuesta macrorregional desde los Sistemas de Información Geográfica. En V. Cortegoso, V. Durán y A. Gasco (Eds.), Arqueología de Ambientes de Altura de Mendoza y San Juan (Argentina) (pp. 275-305). Mendoza: EDIUNC.

» Marchione, P. y Bellelli, C. (2013). El trabajo del cuero entre los cazadores-recolectores de la Patagonia centro-septentrional. Campo Moncada 2 (valle medio del río Chubut). Relaciones de la Sociedad Argentina de Antropología, XXXVIII, 223-246.

» Marsh, E., Cortegoso, V. y Castro, S. (2016). Hunter-gatherer mobility decisions and synchronous climate change in the Southern Andes: The Early and Middle Holocene occupations of ARQ-18, San Juan, Argentina (29.5 ${ }^{\circ}$ ). Quaternary Internacional, 422, 66-80.

»Martínez, J. G. (2007). Ocupaciones humanas tempranas y tecnología de caza en Antofagasta de La Sierra, Puna meridional argentina (10000-7000 AP). CazadoresRecolectores del Cono Sur. Revista de Arqueología, 2, 129-150.

» Méndez, C., Gil, A., Neme, G., Delaunay, A., Cortegoso, V., Huidobro, C., Durán, V. y Maldonado, A. (2015). Mid Holocene radiocarbon ages in the Subtropical Andes ( 29 ${ }^{\circ}$ $35^{\circ} \mathrm{S}$ ), climatic change and implications for human space organization. Quaternary Internacional, 30, 1-12. 
» Méndez, C. y Jackson, D. (2008). La Ocupación Prehispánica de Combarbalá (Norte Semiárido, Chile): Una Propuesta Sintética. Chungara. Revista de Antropología Chilena, 40(2), 107-119.

» Morales, M., Barberena, R., Belardi, J. B., Borrero, L., Cortegoso, V., Durán, V., Guerci, A., Goñi, R., Gil, A., Neme, G., Yacobaccio, H. D. y Zárate, M. (2009). Reviewing human-environment interactions in arid regions of southern South America during the past 3000 years. Palaeogeography, Palaeoclimatology, Palaeoecology, 281(3-4), 283-295.

» Nelson, M. (1991). The Study of Technological Organization. Archaeological Method and Theory, 3, 57-100.

" Núñez, L., Grosjean, M. y Cartagena, I. (2002). Human Occupations and Climate Change in the Puna de Atacama, Chile. Science, 298, 821-824.

»Olivera, D. (2001). Sociedades agropastoriles tempranas: el Formativo Inferior del Noroeste Argentino. En E. Berberian y A. Nielsen (Eds.), Historia Argentina Prehispánica (pp. 83-125). Córdoba: Brujas.

»Parry, W. J. y Kelly, R. L. (1987). Expedient core technology and sedentism. En J. K. Johnson y C. A. Morrow (Eds.), The Organization of Core Technology (pp. 285-304). Boulder: Westview Press.

"Pintar, E. (2004). Cueva Salamanca 1: ocupaciones altitermales en la Puna Sur (Catamarca). Relaciones de la Sociedad Argentina de Antropología, XXIX, 357-366.

»Ratto, N. (2003). Estrategias de Caza y Propiedades de Registro Arqueológico en la Puna de Chaschuil (Dpto. de Tinogasta, Catamarca, Argentina). (Tesis Doctoral inédita), Universidad de Buenos Aires, Argentina.

» Schiffer, M. B. (1987). Formation Processes of the Archaeological Record. Albuquerque: University of New Mexico Press.

» Shott, M. J. (1986). Technological Organization and Settlement Mobility: An Ethnographic Examination. Journal of Anthropological Research, 42(1), 15-51.

"Solar, C., Méndez, C., Jackson, D. y López, P. (2010). Tecnología Lítica y Áreas de Actividad en un Contexto de Cazadores-Recolectores en el Norte Semiárido de Chile. Revista Chilena de Antropología, 22, 57-76.

» Tachikawa, T., Hato, M., Kaku, M. y Iwasaki, A. (2011). Characteristics of ASTER GDEM version 2. En International Geoscience and Remote Sensing Symposium (IGARSS) (pp. 3657-3660).

" Tobler, W. (1993). Three presentations on geographical analysis and modeling, http:// www.geodyssey.com/papers/tobler93.html (Acceso: 15 abril, 2012).

» Tomka, S. A. (1993). Site abandonment behavior among transhumant agropastoralists: the effects of delayed curation on assemblage composition. En C. M. Cameron y S. A. Tomka (Eds.), Abandonment of Settlements and Regions. Ethnoarchaeological and Archaeological Approaches (pp. 11-24). Cambridge: Cambridge University Press.

» Torrence, R. (1983). Time budgeting and hunter-gatherer technology. En G. Bailey (Ed.), Hunter-Gatherer Economy in Prehistory (pp. 11-22). Cambridge: Cambridge University Press.

" Torrence, R. (1986). Production and Exchange of Stone Tools. Cambridge: Cambridge University Press.

» Torrence, R. (1989). Retooling: Towards a Behavioral Theory of Stone Tools. En R. Torrence (Ed.), Time, Energy and Stone Tools (pp. 57-66). Cambridge: Cambridge University Press. 
» Veit, H. (1996). Southern Westerlies during the Holocene deduced from geomorphological and pedological studies in the Norte Chico, Northern Chile $\left(27-33^{\circ} \mathrm{S}\right)$. Palaeogeography, Palaeoclimatology, Palaeoecology, 123(1-4), 107-119.

»Weitzel, C., Flegenheimer, N., Colombo, M. y Martinez, J. (2014). Breakage Patterns on Fishtail Projectile Points: Experimental and Archaeological Cases. Ethnoarchaeology, 6, 81-102.

»Yacobaccio, H. D. (2006). Intensificación económica y complejidad social en cazadoresrecolectores surandinos. Boletín de Arqueología PUCP, 10, 305-320.

» Yacobaccio, H. D., Morales, M. R., Solá, P., Samec, C. T., Hoguin, R. y Oxman, B. I. (2013). Mid-Holocene occupation of the Dry Puna in NW Argentina: Evidence from the Hornillos 2 rockshelter. Quaternary International, 307, 38-49.

»Zech, R., Kull, C. y Veit, H. (2006). Late Quaternary glacial history in the Encierro Valley, northern Chile $\left(29^{\circ} \mathrm{S}\right)$, deduced from 10 Be surface exposure dating. Palaeogeography, Palaeoclimatology, Palaeoecology, 234, 277-286. 